\title{
Reply: long-term retention rate of pramipexole in the treatment of Parkinson's disease
}

\author{
Maurits E. L. Arbouw • Kris L. L. Movig • \\ Jeroen P. P. van Vugt • Toine C. G. Egberts
}

Received: 13 May 2009 / Accepted: 15 May 2009 /Published online: 3 June 2009

(C) The Author(s) 2009. This article is published with open access at Springerlink.com

To the editor:

Keränen and colleagues have investigated the retention rate on pramipexole (PRX) among patients diagnosed with idiopathic Parkinson's disease (PD) in a University Hospital in Finland. Moreover, they investigated reasons for PRX discontinuation, and they tried to identify determinants for PRX discontinuation. We welcome their study as a first initiative to identify reasons for discontinuation and possible determinants.

The authors pointed out that they found a retention rate of PRX in PD patients that was higher (63\% at 3 years) than we found in our cohort (40\% at 3 years) [1], despite similarities in patient characteristics. We agree that differences in study methods may have contributed to variation in findings. In our study, we assessed the (dis)continuation of PRX treatment with prescription data from pharmacies whereas Keränen et al. used records of physicians. In our opinion, several factors have to be taken into account. Firstly, it is possible that not all

M. E. L. Arbouw · T. C. G. Egberts

Department of Clinical Pharmacy,

University Medical Center Utrecht,

Utrecht, The Netherlands

M. E. L. Arbouw • T. C. G. Egberts

Division of Pharmacoepidemiology and Pharmacotherapy,

Utrecht Institute for Pharmaceutical Sciences, Faculty of Science,

Utrecht University,

Utrecht, The Netherlands

M. E. L. Arbouw $\cdot$ K. L. L. Movig

Department of Clinical Pharmacy, Medisch Spectrum Twente,

Enschede, The Netherlands

J. P. P. van Vugt

Department of Neurology, Medisch Spectrum Twente,

Enschede, The Netherlands

T. C. G. Egberts $(\triangle)$

Department of Clinical Pharmacy, Division Laboratory

and Pharmacy, University Medical Center Utrecht,

PO Box 85500, 3508 GA Utrecht, The Netherlands

e-mail: a.c.g.egberts@umcutrecht.nl changes in medication (discontinuation, dose changes) are written down in medical records. Therefore, some patients that have discontinued could be missed. Secondly, there remains a possibility that some patients have discontinued their medication without informing their physician. There is evidence for non-adherence in patients with PD measured with a computerised monitoring system [2]. However, studies investigating whether patients actually get their medication from the pharmacy are lacking. Lastly, the number of visits to the treating physician (in the study of Keränen et al.) or to the pharmacy (in our study) could be a factor in the precision of the estimation of discontinuation. The mean length of PRX prescriptions in our study was 47 days. This implies that we had an evaluation moment (use or no use) every 47 days. We do not know the frequency of visits to the treating physician in the study of Keränen et al.

Keränen et al. found two non-genetic factors that were associated with PRX discontinuation: orthostatic hypotension and entacapone treatment prior to PRX treatment. These findings are an interesting supplement to our study. We think, however, that genetic factors should also be studied in the future [3].

Open Access This article is distributed under the terms of the Creative Commons Attribution Noncommercial License which permits any noncommercial use, distribution, and reproduction in any medium, provided the original author(s) and source are credited.

\section{References}

1. Arbouw ME, Movig KL, Guchelaar HJ, Poels PJ, van Vugt JP, Neef C, Egberts TC (2008) Discontinuation of ropinirole and pramipexole in patients with Parkinson's disease: clinical practice versus clinical trials. Eur J Clin Pharmacol 64:1021-1026

2. Leopold NA, Polansky M, Hurka MR (2004) Drug adherence in Parkinson's disease. Mov Disord 19:513-517

3. Arbouw ME, van Vugt JP, Egberts TC, Guchelaar HJ (2007) Pharmacogenetics of antiparkinsonian drug treatment: a systematic review. Pharmacogenomics 8:159-176 